\section{La vigencia de un clásico: Maquiavelo}

\section{Yohnny Azofeifa Sánchez*}

\section{Resumen}

El presente artículo discute y explora la figura y algunos de los temas fundamentales de un autor que consideramos altamente significativo para comprender nuestra apresurada y veloz modernidad "liquida" (Z.Bauman). Esta figura es la del genial secretario florentino, Nicolás Maquiavelo. Es por ello que presentamos algunas valoraciones que se han hecho sobre su persona y sobre su texto imperecedero El Príncipe -considerado la Biblia de los políticos- enfatizando en la compleja relación entre ética y política, tema que tanto ha dado de que hablar en los últimos 400 años. Asimismo se pone énfasis en su irrefutable vigencia y actualidad. Esperamos con este trabajo hacerle honor y contribuir a la mejor comprensión y discusión de este fundamental autor del pensamiento y la teoría política de todos los tiempos.

\section{Palabras clave}

Imagen de Nicolás Maquiavelo, Temas fundamentales, Valoraciones, Ética, Teoría politica.

* Licenciado en Filosofía por la Universidad de Costa Rica. Actualmente es profesor de la Escuela de Estudios Generales, UCR, y de la UNED. Ha publicado otros ensayos sobre el tema.

Rec. 14-11-05 Acep. $28-03-06$

\section{Abstract}

This article discusses and analyzes the image and some of the main topics of an author considered highly significant for the understanding of our accelerated "Liquid" Modernity ( $Z$. Bauman).umber of reviews on him and on his imperishable work "The Prince," which is considered the Bible of all politicians; it also makes emphasis on the complex relationship between ethics and politics, a topic that has been thoroughly analyzed for the last 400 years, confirming, therefore, its unarguable force and prevalence.This article is meant to honor Machiavelli and contribute to a better understanding of such an important author of thinking and of all-time theory of politics.

\section{Keywords}

Nicolas Machiavelli image, Main topics, Reviews, Ethics, Theory of politics.

$$
\begin{gathered}
\text { Nicolás Maquiavelo: Ningún epitafio } \\
\text { iguala a tan gran nombre } \\
\text { (Inscripción en la tumba). }
\end{gathered}
$$

\section{A modo de Introducción:}

\section{El influjo de una leyenda}

En los últimos quinientos años muy pocos nombres (e ideas y libros asociados a los mismos) en la historia universal de Occidente han causado mayores desacuerdos y controversias que el de Nicolás 
Maquiavelo, y todos los que han escrito sobre él, desde las más disímiles perspectivas, lo consideran como uno de los más significativos pensadores. Sin duda alguna, quien lo lea hoy no puede menos que sentir que las cuestiones que él debate siguen siendo las de nuestra convulsa época.

¿Quién fue este singular y enigmático personaje conocido por la historia como el Secretario Florentino?, quien se presentaba a sí mismo, ante sus amigos, como: "...historiador, cómico y trágico...". Fue, indudablemente, un hombre fascinante, ciudadano, y funcionario, político y teórico, poeta e historiador, autor de obras de teatro, hombre de acción y de meditación.

Ernst Cassirer afirma en su justamente célebre libro, que de toda la historia de la literatura El Príncipe de Maquiavelo es la mejor prueba del aserto latino: "La fortuna de un libro depende de la capacidad de sus lectores" (Cassirer, 1968:138). La fama de este pequeño tratado desde su publicación ha sido única $\mathrm{y}$ sin precedentes aún en nuestros días. Esta obra no se ha leído para satisfacer curiosidades intelectuales; desde sus primeros lectores, El Príncipe, de Maquiavelo, fue puesto inmediatamente en acción, $\mathrm{y}$ a través del tiempo ha sido puesto como un arma poderosa y peligrosa en las grandes luchas políticas de nuestro mundo moderno.

Sus efectos eran claros e indudables. Pero, en cierto modo, su sentido permanece secreto. Aún ahora, cuando su libro ha sido abordado desde todos los ángulos, después de ser discutido por filósofos, historiadores, políticos y sociólogos, este secreto no ha sido todavía completamente revelado. De un siglo a otro, casi de generación en generación, encontramos no sólo un cambio, sino una inversión completa de los juicios sobre El Príncipe. Lo mismo puede decirse sobre el autor del libro. La imagen de Maquiavelo, confusa por el amor y el odio de otros, ha cambiado en la historia; y es extremadamente difícil reconocer, detrás de todas esas variaciones, la efigie verdadera del hombre y el tema de su libro (Cassirer, 1968:138).

En época de la historia del pensamiento humano resulta ocioso afirmar que Nicolás Maquiavelo ocupa un lugar único, irrepetible en el panorama del pensamiento político occidental, epítome de ese singular período histórico que 
conocemos como: Renacimiento (filósofo y teórico de la política de extremada originalidad, literato y escritor inimitable, historiador erudito como pocos, conocedor de todas las artes) fue el pensador político de mayor lucidez de su tiempo, conciente de las grandes tareas histórico-políticas de la nueva época cuyo parto le correspondió como privilegiado testigo presenciar.

La secularización de la política -es decir, la separación entre la especificidad de la praxis política, de sus leyes como conformadora de la polis por un lado, y por otro la heteronomía teológica y eclesiástica a la cual la política estaba tradicionalmente sometida desde la caída del Imperio Romano -y la conformación de los grandes Estados nacionales centralizadoses decir, la ambigua forma política que adquiere la organización territorial, administrativa, militar y económica de lo que Marx llamaría el incipiente proceso de acumulación capitalista- son las ciclópeas demandas de la hora, cuya problemática Maquiavelo se propuso explorar hasta sus últimas consecuencias, en el curso de cuya exploración descubre tendenciales "leyes" de lo político que van mucho más allá de la coyuntura histórica.
Nicolás Maquiavelo es uno de los teóricos de la política más controvertido e influyente de todos los tiempos, lo que resulta una auténtica obviedad, admirado y odiado por igual; la valoración de su obra El Príncipe ha hecho correr ríos de tinta. Quienes la han adversado consideran a éste un mero breviario de bellaquerías y maledicencias, y que su autor, no es más que un sinvergüenza y perverso que postuló las peores bajezas como características propias de la política, que, entre otras cosas, legítimo y justificó la violencia y la coacción de los gobernantes sobre los gobernados, a partir de un principio irrefutable: la maldad intrínseca del ser humano.

A través de la historia, y según sean los vientos que corren, al secretario florentino se le ha presentado como un cínico total, un jesuita político, un patriota apasionado, un nacionalista ardiente, un adulador carente de escrúpulos que buscaba el favor de los poderosos. El ilustrado Federico II, Rey de Prusia, lo calificó como"el enemigo de la humanidad". En su Antimaquiavelo expresa: "Maquiavelo corrompió la política y se empeñó en destruir los preceptos de la sana moral. Siempre he considerado El Príncipe como una de las obras más peligrosas que se han propagado por el 
mundo (...) La trapacería y la perversidad de Maquiavelo se hallan esparcidas en esta obra como el apestoso olor de un vertedero que se propala al aire del entorno" (Cardona de Gilbert, 1973:60).

El genial Voltaire lo llamó "el doctor del crimen", también "el ponzoñoso Maquiavelo". Shakespeare se refirió a él como el "sanguinario Maquiavelo". El influyente historiador Leo Strauss, quien le denomina "el maestro del mal", afirma que Maquiavelo "es el único pensador político cuyo nombre ha entrado en el uso común para designar un tipo de política guiada exclusivamente por consideraciones de conveniencia, que emplea todos los medios, justos o injustos, el acero y el veneno, para alcanzar sus fines", Para el pensador católico Jacques Maritain, la separación entre ética y política propuesta por Maquiavelo constituye el gran problema de su pensamiento, señalando que la responsabilidad histórica del autor renacentista "radica en que él acepto, reconoció y asumió como regla el factum de la inmoralidad política; y en que declaró que la buena política, es decir, la política que corresponde a su naturaleza y a sus verdaderos fines, es esencialmente una política sin moral" (Cardona de Gilbert, 973:61). Una política inmoral que ha corrompido desde Maquiavelo a los políticos y a los teóricos de la política, desde Catalina de Médicis hasta Hitler, pasando por Carlos V, el Cardenal Richelieu y Napoleón I, quien dijo que "de todas las obras políticas que vale la pena su lectura (...) la única es la de Maquiavelo".

Quienes lo han admirado y alabado, han dicho que El Príncipe es el primer tratado político del pensamiento moderno. El nacimiento de la ciencia política fue señalado por el genial secretario a través de la diferencia que establece entre la política y la religión. Para el filósofo inglés Francis Bacon, lo más importante de este tratado lo constituye su afirmación de que la política tiene como norte no la idea de un deber ser, sino la verdad política -veritá effettuale-, es decir, cómo son las cosas en el mundo y lo seguirán siendo en tanto haya hombres. Escribe al respecto: "Debemos mucho a Maquiavelo y a otros escritores de esta clase, los cuales manifiestan o describen claramente y sin ficción lo que los hombres hacen, y no lo que debieran hacer" (Cortés Rodas, 2001:189).

Insospechables pensadores considerados los ideólogos fundadores de los regímenes de democra- 
cia liberal moderna, como son B. Spinoza y J.J. Rousseau expresaron una gran admiración hacia el sospechoso de marras, considerándolo ante todo un campeón de las libertades. A juicio del filosofo holandés: "los medios que un Príncipe, cuyo único motivo es el afán de dominio, debiera emplear para establecer y mantener este dominio, el muy ingenioso Maquiavelo los ha expuesto extensamente; pero es difícil decir con qué intención lo hizo. Tal vez deseaba indicar que una masa libre debiera ser muy precavida al confiar su bienestar absolutamente a un hombre solo, el cual tiene que sentir el permanente temor de las conjuras, y ello lo obliga a cuidar principalmente de su propio interés; $y$, en cuanto a la masa, más bien a conspirar contra ella que a consultarla sobre su propio bien. $\mathrm{Y}$ me siento tanto más inclinado a esta opinión relativa a este hombre tan previsor, cuanto que es sabido que era partidario de la libertad, para el mantenimiento de la cual, además, supo dar los más sanos consejos" (Cortés, 2001:190). El ginebrino por su parte, anota que: "con el pretexto de enseñar a los reyes, instruyó realmente al pueblo. El Príncipe de Maquiavelo es en verdad el libro de los republicanos" (Idem).
Por su parte una de las cumbres de la filosofía de todos los tiempos, culmen del idealismo alemán, Jorge Federico Hegel confesaba que en su época juvenil de Jena: "soñó en convertirse en un segundo Maquiavelo; en el Maquiavelo de su propio tiempo, encontró que había un exacto paralelo entre la vida pública alemana en el siglo XIX y la vida nacional italiana en el periodo de Maquiavelo". En un tratado inédito sobre la constitución de Alemania afirma:

Del hondo sentimiento de la miseria general de Italia, del odio, el desorden y la ceguera, un político italiano concibió con fría circunspección la idea necesaria de la liberación de Italia. Por medio de su unión en un solo Estado. Carece de sentido tratar el desarrollo de una idea que se formó en la observación de las condiciones en que se encontraba Italia, como si fuera un sumario desinteresado de principios morales y políticos, aplicables a toda situación, y por ello aplicables a ninguna. Hay que leer El Príncipe tomando en consideración la historia de los siglos anteriores a Maquiavelo, y la historia de su tiempo; y entonces esta obra no sólo está justificada, 
sino que aparece como la verdadera concepción, elevada y magnífica, de un auténtico genio político, del más grande y más noble de los espíritus. (Citado Cortés, 2001:190)

Para Carl Schmitt, considerado el filósofo del Reich Alemán, y de lectura obligada entre los militares golpistas del Cono Sur de todas las épocas, Maquiavelo es el prototipo del pensador específicamente político porque parte de concebir la naturaleza humana como cosa problemática; en su influyente y cada vez más estudiada obra, señala que: "todas las teorías políticas propiamente dichas, presuponen que el hombre es "malo", y lo consideran como un ser no sólo problemático sino "peligroso" $\mathrm{y}$ dinámico. Bastará con mencionar aquí el nombre de Maquiavelo.

El referido neokantiano Ernst Cassirer considera que el secretario florentino es un técnico frío, -un tecnócrata diríamos hoy, paradigma del consultor postmoderno y descafeinado- no comprometido ni ética ni políticamente, un científico moralmente neutral. En su justamente célebre El mito del Estado señala que: "Maquiavelo estudió y analizó los movimientos políticos con el mismo espíritu con que Galileo estudió, un siglo después, el movimiento de los cuerpos al caer. Fue el fundador de un nuevo tipo de ciencia de la estática y la dinámica políticas" (Cassirer, 1968:139). En esta interpretación, el Estado es completamente independiente, pero al mismo tiempo está totalmente aislado. Al separar la moral de la política, el Estado queda libre de toda valoración ética. En igual sentido, otro de los exegetas famosos del pensador florentino, Federico Chabod, en sus conocidos Escritos sobre Maquiavelo, advierte que El Príncipe:

nacido del impulso de una finalidad práctica inmediata, se convierte en la obra clásica de la teoría política, la obra en la cual, por primera vez desde que el mundo era cristiano, se afirma el principio de autonomía del quehacer político, respecto de toda premisa y finalidad metafísicas, su autonomía respecto de las demás formas de actividad humana $\mathrm{y}$, en primer lugar, respecto de la moral (Citado por Cortés, 2001:191).

Otra interpretación que se ha hecho fama es la del teórico Eric Vogelin, para quien la clave de la interpretación de la ética de Maquiavelo descansa en el reconocimiento del hecho elemental de que la existencia de los seres humanos está atravesada por conflictos de valores. 
Así, si uno considera como principio supremo de las acciones el tipo de moralidad que parte del principio platónico de que hacer el mal es peor que soportarlo, uno queda imposibilitado en la realidad de su vida para la realización de otros valores que, de todas formas, están incorporados en el ser humano.

Contemporáneamente, el autor más renombrado del tinglado filosófico, J. Habermas, valora el que Maquiavelo disuelve el saber práctico de la política en una habilidad técnica. Contrariamente a los antiguos, donde la dirección del Estado debía unir a la sabiduría un cierto poder, en el florentino de la política solo queda la competencia artesanal del estratega. Se convierte entonces en un "arte" que no tiene el modelo en el canon de las artes tradicionales: tal es el auténtico descubrimiento de Maquiavelo:

Este arte de la conducción de los hombres, como diríamos hoy en día, también es a su manera un poder técnico, pero tiene como material de trabajo (lo cual sería inconcebible para los antiguos) en lugar de los objetos de la naturaleza, el comportamiento humano). El comportamiento del mismo hombre, en especial sus impulsos de autoafirmación y sumisión, son la materia que tiene que conformar el principesco artesano. Maquiavelo aún llega a sus intelecciones psicológicas a la manera casuística del historiador, pero se expresa con total claridad la intención técnica de ejercita la política como saber del dominio para erigir un regnum hominis también sobre la sometida historia (Habermas 1990:65-66).

Hace suyo el comentario de uno de sus maestros, el frankfurtiano Max Horkheimer, respecto a que la grandeza de Maquiavelo consiste... en haber reconocido la posibilidad de una ciencia de la política correspondiente a la nueva física y psicología y a sus principios, $y$ en haber expresado sus rasgos esenciales, sencilla y determinantemente. A su juicio, esta interpretación adelanta a Maquiavelo en la medida en que la habilidad de conquista y conservación (y aumento, agregamos nosotros) del poder surge, ciertamente, a partir de una transferencia de la techné artesanal al campo, hasta entonces reservado a la phronesis, de la praxis, pero aún carece de la precisión científica de la técnica calculadora. Concluyendo que de esta manera "la pretensión de una fundamentación de la política según 
los principios del ideal galileano de ciencia sólo puede surgir en el marco de una imagen mecanicista del mundo" (Habermas, 1990:66).

\section{Estructura y contenido de El príncipe}

Como es conocido, se abre el libro con una dedicatoria de "Nicolás Maquiavelo al magnífico Lorenzo de Médicis". En ella se habla claramente de lo que el secretario florentino ofrece a su posible empleador:

...deseando ofrecerme a Vuestra Magnificencia con un testimonio (...), no he encontrado(...), cosa alguna de más valor y aprecio que el conocimiento de las acciones de los grandes hombres.

Inmediatamente, y en la misma dedicatoria, da cuenta de las fuentes: la experiencia y los autores de la Antigüedad, especialmente los historiadores latinos.

La obra en cuestión consta de 26 capítulos cortos, sin elementos sobrantes que contribuyan a dilatar las cuestiones o a demostrar que existe el más mínimo esteticismo. Sinteticemos, a continuación, el título y el contenido de los primeros nueve capítulos que pueden considerarse la primera parte.
I. Clases de principados y modo de adquirirlos.

II. De los principados hereditarios.

III. De los principados mixtos

IV. Por qué razón el reino de Darío, ocupado por Alejandro, no se rebeló contra los sucesores de éste después de su muerte.

V. De qué manera se debe gobernar los Estados que, antes de ser ocupados por nuestro príncipe, se regían por sus propias leyes.

VI. De los principados nuevos que se adquieren con el valor personal y con las armas propias.

VII. De los principados nuevos que se adquieren con la fortuna y las armas ajenas.

VIII. De los que llegaron al principado por medio de maldades.

IX. Del principado civil.

Siguiendo el excelente estudio introductorio de la autora catalana Ángeles Cardona de Gilbert, afirmemos que estos títulos en lo esencial se pueden sintetizar de la siguiente manera: Maquiavelo está tratando de cómo se crea y se forma un principado. Con respecto 
al capítulo I nada hay que agregar. Con respecto a los hereditarios (Cap. II), cosa sencilla va a ser el gobierno, puesto que el príncipe "no necesita más que traspasar el orden seguido por sus mayores". $Y$ supone que, aun surgiendo una fuerza extraordinaria que le privara del Estado, el príncipe "acabaría recuperándolo por muy poderoso y hábil que fuera el usurpador que se hubiera apoderado de él. Pasando a continuación a ejemplificar, de forma concreta, ensalzando a sus contemporáneos.

Curiosamente, el capítulo III considera que el príncipe tiene grandes dificultades en su gobierno, precisamente porque se trata de un miembro añadido a un principado antiguo. $\mathrm{Y}$ es que este principado se consiguió por la loca pretensión que tienen algunos hombres, los cuales, cansados de su antiguo señor, ponen en su lugar, con las armas, a otro nuevo, con la esperanza de que va a gobernarles mejor. El príncipe se enfrenta entonces con unos enemigos creados por la situación. Es decir, serán sus enemigos todos los que eran partidarios del antiguo señor. Por eso, se coloca en pie de guerra, y de ahí las dificultades. Pasa a la ejemplificación, como siempre. Aquí los casos expuestos afectan a personajes y hechos contemporáneos y de la Antigüedad. Es curiosa la máxima general con que termina el capítulo, puesta como comentario a las guerras entre España y Francia aliada con el Papado: "El que ayuda a otro a hacerse poderoso provoca su propia ruina".

Por su parte, el capítulo IV está montado sobre el sistema de interpretación histórica, con lo cual Maquiavelo crea unas bases de filosofía de la historia muy sugerentes, aunque no son ellas las que ahora nos interesan, sino sus concepciones políticas. Así pues, entre los capítulos III y V se impone el análisis de las conquistas de nuevas provincias por parte de un Estado, ya formado y organizado, y sus conclusiones son de sumo interés.

Los capítulos III y IV los dedica el florentino a la formación de un nuevo principado. Pone como ejemplo los de Francisco Sforza y César Borgia. Estos ejemplos, sacados de la experiencia directa y contemporánea, son muy valiosos, pero al referirse a Borgia, exagera la grandeza de sus propósitos y, cuando concede importancia a la fortuna, como base para explicar la caída vertical del personaje ensalzado, la explicación -nos parece- resulta demasiado fácil y la justificación un tanto pueril. 
Estos nueve primeros capítulos forman un todo unitario y exponen los procesos de creación y formación de un principado. Al añadir a esta unidad el capítulo $X$, Maquiavelo expondrá la capacidad general de lucha de un Estado contra el enemigo exterior.

Haciendo un corte con el discurso anterior, en el capítulo XI se nos habla de la Iglesia, un Estado singular, distinto a todos los demás, para él que no valen las leyes que rigen en los otros. Maquiavelo lo sabía, y como lo afirma el renombrado autor $G$. Sabine "pese a que los papas del tiempo de nuestro autor eran con frecuencia indignos $y$ libertinos, consiguieron hacer de su Estado el más consolidado y fuerte de Italia" (Sabine, 1972:252).

XII. De las diferentes especies de tropas, y de los soldados mercenarios.

XIII. De los soldados auxiliares, mixtos y propios.

XIV. De las obligaciones del príncipe en lo que concierne al arte de la guerra.

En estos capítulos, dura y quizás injustamente, Maquiavelo se refiere a una institución muy utilizada por los gobernantes de su época, cual es el de las tropas mercenarias y denuncia el grave fallo en que, al haberlas acogido, han caído los príncipes italianos. Por ello, aconseja la formación de una milicia propia, por parte de cada Estado. Y después de hablar de esta necesidad vital que es estar preparado para la guerra, se da cuenta -como es de esperar- de que hay en un Estado otros motivos de preocupación: problemas económicos, financieros, de orden interior, pero como lo absorbe "la guerra" no los trata y pasa en los cuatro capítulos siguientes a observar las cualidades que debe tener el príncipe para mantenerse tranquilo en su Estado.

$\mathrm{XV}$. De las cosas por las que los hombres, y especialmente los príncipes, son alabados o censurados.

XVI. De la liberalidad y de la avaricia.

XVII. De la crueldad y de la demencia, y si vale más ser amado que ser temido.

XVIII. De qué modo los príncipes deben guardar la fe dada.

Sin duda es esta la parte de la obra que ha dado más que hablar y de la cual se han escrito cientos de interpretaciones. La dureza y el comportamiento realista que se le exige al príncipe, tanto en su con- 
ducta privada (no dilapidar para no tener que recargar con impuestos) como pública (es preferible ser cruel a tiempo), ha sido la base de los ataques de inmoralidad al autor.

El capítulo XVIII es el más discutido; en efecto, Maquiavelo juega con la antitesis conceptual: "Es elogiado sobremanera un príncipe cuando mantiene la fe que ha jurado...". No hay quien no comprenda esta verdad y, sin embargo, la experiencia de nuestros días muestra que varios príncipes, desdeñando la buena fe y empleando la astucia para reducir a su voluntad el espíritu de los hombres, realizaron grandes empresas $\mathrm{y}$ acabaron por triunfar de los que procedieron en todo con lealtad. Es necesario que el príncipe sepa que dispone de dos recursos para defenderse: la ley y la fuerza. $\mathrm{Y}$ aunque, añade, "la primera es propia del hombre, la segunda lo es de los animales", continúa, "pero como muchas veces la primera no basta, conviene recurrir a la segunda" (Cardona de Gilbert, 1973:35). Pasando a continuación a comentar la alegoría de los antiguos, muchos de cuyos generales fueron educados, en parte, por un león. Y poco a poco, después de señalar al príncipe que esté alerta, porque puede darse el caso de que haya de actuar más como fiera que como hombre, llega a la consideración que le ha dado más fama y por el cual ha sido impugnado y censurado. "Procure, pues, un príncipe conservar y mantener el Estado. Los medios que emplee serán siempre considerados honrosos y alabados por todos".

Es quizás, junto a la socrática y a la cartesiana, de las más famosas frases "filosóficas" de la historia: "El fin justifica los medios", máxima, por cierto, no dicha en esta forma, como puede verse al leerse la cita anterior.

XIX. De qué modo se debe evitar ser despreciado y odiado.

$\mathrm{XX}$. Si las fortalezas y otras muchas cosas que los príncipes hacen con frecuencia son útiles o no.

XXI. Cómo debe conducirse un príncipe para ser estimado.

XXII. De los secretarios que los príncipes tienen a su lado.

XVIII. De qué modo se debe huir de los aduladores.

Como en todo lo anterior, demuestra en todo momento un profundo conocimiento de los hombres, de la situación política y de la peculiar psicología que los gobierna. 
Para concluir el libro, los capítulos XXIV y XXVI, Maquiavelo los dedica a su Italia natal, estableciendo nuevas perspectivas políticas. El libro cambia ahora el sistema expositivo de que antes se sirvió el autor y pasa a examinar las causas por las que han perdido sus Estados distintos príncipes italianos. Se trata también el tema de la fortuna (Cap. XXIV) tema muy renacentista. Se analiza si es posible enfrentarse $\mathrm{y}$ vencer a la fortuna (Cap. XXV). Maquiavelo opina que en sus días un buen príncipe puede hacer frente a la fortuna y constituirse príncipe de un nuevo Estado que se oponga a "los bárbaros" y los barra del "bárbaro dominio" ocupado por franceses y españoles. La obra se cierra con los versos de Francesco Petrarca que posiblemente habían consolado a nuestro autor en su triste destierro.

Italia mía: el esfuerzo contra el furor/ tomará las armas y hará el combate corto/ que el antiguo valor/ en el itálico corazón no ha muerto aún (Idem, 36).

Es como si líricamente rematara la obra pidiendo un liberador para la Italia dividida. $Y$ aunque el libertador, del que ya hablamos, por mucho que uniera sólo gobernaría en la Italia central del momento, creemos que la invocación del capítulo XXVI es una de las más poderosas manifestaciones que han salido de pluma alguna.

\section{Acerca de la compleja relación entre moral y política}

Moralidad y política son términos que a través de la historia han casado mal, particularmente en periodos de descomposición social como la actual, donde priva la corrupción y la insolidaridad, y donde las relaciones entre los países se fundamentan en la ley del garrote y en el atropello de los más elementales derechos humanos.

Maquiavelo es en "nuestra" modernidad inconclusa (Habermas), sin duda, el autor donde podemos identificar de manera más desgarradora la tensión de este complejo y explosivo maridaje.

Desde los griegos hasta el medioevo, los tratadistas políticos hicieron prescripciones, escribieron sobre el deber ser, esto es, cómo han de comportarse los gobernantes, nuestro autor se aparta de estos métodos y afirma que "... siendo mi propósito escribir algo útil para quien lo lea, me ha parecido más conveniente ir directamente a la verdad real (verita effettuale) de la cosa que a la representación ima- 
ginaria de la misma..." (Cortés, 2001:194). Agrega que muchos “... se han imaginado repúblicas y principados que nadie ha visto jamás ni se ha sabido que existieran realmente; porque hay tanta distancia de cómo se vive a cómo se debería vivir, que quien deja de lado lo que hace por lo que debería hacer, aprende antes su ruina que su preservación..."). (El Príncipe, Cap.XV)

Si examinamos los tratados morales de los contemporáneos de Maquiavelo, encontramos estos argumentos repetidos incansablemente. Pero al volvernos hacia El Príncipe hallamos este aspecto de la moralidad humanística drástica y visiblemente trastocado. El cambio comienza en el capítulo 15, momento en el que Maquiavelo empieza a tratar de las virtudes y vicios de los príncipes y nos avisa que aunque "muchos han escrito sobre esto", él va a "partir muy lejos de los métodos de los demás". Comienza haciendo alusión a lugares comunes de la tradición humanista: que hay un grupo especial de virtudes principescas: que estas incluyen la necesidad de ser generoso, misericordioso, $\mathrm{y}$ veraz; y que todos los gober- nantes tienen la obligación de cultivar esas cualidades. Admite seguidamente -todavía dentro de la ortodoxia humanista- que "sería muy loar en un príncipe" ser capaz de obrar en todo tiempo de esta manera. Pero en ese momento rechaza totalmente el supuesto humanista de que esas son las virtudes que un gobernante necesita adquirir si quiere alcanzar lo más altos fines. (Skinner, 1991:51).

Siguiendo a este renombrado historiador, señalemos cómo Maquiavelo ve en esta idea -nervio y corazón de los libros renacentistas conocidos como "espejos de príncipes", un palmario y desastroso error. Está de acuerdo con ellos acerca de la naturaleza de los fines perseguidos: todo príncipe debe procurar mantener su estado y obtener gloria para sí mismo, pero objeta que si es preciso obtener esos objetivos, ningún gobernante puede quizás "poseer o practicar íntegramente" todas las cualidades que son normalmente "consideradas buenas". La posición en que todo príncipe se encuentra es la de procurar proteger sus intereses en un mundo sombrío, -como es, también, el nuestro inicios del globalizado segundo milenio- en el que la 
mayoría de los hombres "no son buenos". Se sigue de esta lógica realista que si él "insiste en hacer que sus negocios sean buenos" en medio de tantos que no lo son, no solamente fracasará en la obtención de "grandes cosas" sino que "seguramente será destruido".

En la valoración del citado historiador, la crítica que hace Maquiavelo del humanismo clásico y del contemporáneo es simple pero devastadora. Argumentará que si un gobernante quiere alcanzar sus más altos propósitos, no siempre debe considerar racional el ser moral; por el contrario, hallará que cualquier intento serio "de practicar todas aquellas cosas por las que los hombres se consideran buenos" acabará convirtiéndose en una ruinosa e irracional política.

Dicho comentarista se pregunta:

Pero ¿qué hay de la objeción cristiana que dice que esta es postura demencial y pecaminosa, pues olvida el día del juicio, en el que finalmente todas las injusticias serán castigadas? Sobre esto Maquiavelo nada dice. $\mathrm{Su}$ silencio es elocuente: en realidad hace época; su eco resuena a través de Europa, recibiendo como respuesta un silencio consternado al principio, y luego un grito de execración que aún no se ha extinguido del todo. (Skinner, 1991:52)

En efecto, si los príncipes no deben conducirse de acuerdo con las normas de la moral convencional, ¿cómo deben hacerlo? La respuesta del secretario florentino -el núcleo de su positivo consejo a los nuevos gobernantes- se ofrece al inicio del señalado capítulo 15 . Un príncipe prudente debe guiarse ante todo por los dictados de la necesidad "para mantener su posición", "debe conseguir el poder de no ser bueno, y aprender cuándo usarlo y cuándo no", según las circunstancias lo indiquen. Esta doctrina fundamental se repite tres capítulos más adelante. Un príncipe prudente "defiende lo que es bueno cuando puede" pero "sabe cómo hacer el mal cuando es necesario". Más aún, debe resignarse ante el hecho de que "se verá necesitado con frecuencia " a actuar " en contra de la verdad, en contra de la caridad, en contra de la humanidad, en contra de la religión" si quiere "mantener su gobierno".

Fruto de sus tempranas experiencias diplomáticas, nuestro autor llega a la siguiente conclusión: si un hombre quiere "gozar siempre de buena Fortuna", debe ser "lo suficientemente prudente como para acomodarse a los tiempos". 
En realidad, agrega Maquiavelo, si cada uno "dominara su naturaleza" de este modo, e "hiciera su camino al compás de su tiempo" entonces "resultaría ser verdad que el hombre prudente se convertiría en dueño de las estrellas y los hados" (Cortés, Idem).

En El Príncipe, el autor renacentista enfatiza el papel de la Fortuna en los asuntos humanos. Todo el mundo, dice, quiere seguir su natural inclinación: uno "actúa con precaución, el otro impetuosamente; el uno por la fuerza, el otro por la maña. Pero entre tanto, "tiempos y negocios cambian", de manera que un gobernante que no "cambie su modo de proceder" se verá obligado, tarde o temprano, a habérselas con la mala suerte. No obstante, si "pudiera cambiar su naturaleza con los tiempos y con los negocios, la Fortuna no cambiará". Así el príncipe triunfador será siempre aquel "que adapta su modo de proceder a la naturaleza de los tiempos". En la valoración del citado Skinner, esto constituye la revolución de Maquiavelo:

Resultará evidente ahora la revolución realizada por Maquiavelo en el gente de los libros de aviso de príncipes estaba basada en efecto en la redefinición del concepto central de virtú. El suscribía la acepción convencional de que virtú es el nombre de aquel conjunto de cualidades que hacen capaz a un príncipe de aliarse con la Fortuna y obtener honor, gloria y fama. Pero separa el sentido del término de cualquier conexión necesaria con las virtudes cardinales y principescas. En lugar de ello argumenta que la característica que define a un príncipe verdaderamente virtuoso debe ser la disposición a hacer siempre lo que la necesidad dicta -sea mala o virtuosa la acción resultante- con el fin de alcanzar sus fines más altos. De este modo virtú denota concretamente la cualidad de flexibilidad moral de un príncipe: "él debe tener siempre su espíritu dispuesto a volverse en cualquier dirección al compás del soplo de la Fortuna y según lo requiera la variabilidad de los asuntos (Skinner 1991:54).

Irónicamente, Maquiavelo hace notar que su perspectiva abre una franja infranqueable con toda la tradición humanista, para la cual la virtud moral definía al vir, el hombre de la verdadera humanidad. La virilidad no es suficiente, pues hay realmente dos maneras de obrar, señala al comienzo del 
capítulo 18, de las que "la primera es propia del hombre y la segunda de los animales". Pero "puesto que la primera con frecuencia no es suficiente, el príncipe debe acudir a la segunda". Una de las cosas que, por lo tanto, el príncipe debe saber, es a qué animales imitar. Famosa es la advertencia del florentino de que llegará a ser el mejor "si elige entre los animales el zorro y el león", complementando la astucia y la fuerza. En el capítulo siguiente, ilustra este consejo con la figura del emperador romano Septimio Severo, quien al actuar bajo esa normativa "fue temido y respetado por todos".

Analizando en los capítulos 19 y 21 las líneas de conducta que son de esperar de un príncipe realmente virtuoso, podemos entender la irrestricta admiración de Maquiavelo por Cesar Borgia, modelo de virtú para otros nuevos príncipes. Refiriéndose al modo como éste solucionó los hechos de la Romagna (la muerte de su representante Ramiro y la exhibición de su cuerpo a la ira del pueblo), el comentarista referido señala que:

La creencia de Maquiavelo en la imperativa necesidad de impedir el odio y el desprecio populares quizás date de este momento. Pero si la acción del duque sirvió simplemente para corroborar su propio sentido de las realidades políticas, no cabe duda de que el episodio lo dejó profundamente impresionado. Cuando se aplica a examinar las consecuencias del odio y del desprecio en $E l$ Príncipe, es precisamente este incidente el que evoca para ilustrar su punto de vista. Deja perfectamente clara que la actuación de Borgia se presentó a su reflexión como profundamente cuerda. Fue decidida, supuso valentía y logró exactamente el efecto deseado, al tiempo que eliminaba sus "motivos de odio". Al resumirlo en el más gélido de los tonos, Maquiavelo recalca que la conducta del duque le parece, como siempre, ser "digna de mención y de ser imitada por los demás (Skinner, 1991:56).

Lúcidamente, Maquiavelo advierte la novedad de sus análisis sobre la virtú principesca y de sus dificultades, como bien lo plantea en el capítulo 15: por un parte, un príncipe debe "adquirir el poder de no ser bueno" y ejercerlo siempre que la necesidad lo exija; pero, por otra parte, debe tener cuidado de no adquirir la reputación de ser un hombre perverso, porque ello 
tendería a "arrebatarle su propia posición" en lugar de consolidarla. El problema consiste, por lo tanto, en evitar aparecer como perverso aún cuando no se pueda impedir comportarse perversamente.

Estamos aquí, sin duda, con uno de los rasgos más modernos de la concepción política de Maquiavelo: el gobernante debe cuidar sobre todo las apariencias; como es fácilmente perceptible en la política cotidiana, nuestros políticos siguen la norma de actuar de una manera diferente a la que prometieron, pero eso sí, aparentando siempre lo que no son; los ejemplos sobrarían.

Maquiavelo se vale del ejemplo de Agatocles, el tirano de Sicilia, para mostrar las dificultades que implica mantener la virtú y alcanzar honor y gloria entre los hombres, actuando de la manera antes referida. Esto hace que:

Finalmente, Maquiavelo se niega a admitir que el dilema pueda resolverse poniendo límites estrictos a la maldad principesca $y$, en general, comportándose honradamente con los propios súbditos y con los aliados. Esto es exactamente lo que no se debe hacer, porque todos los hombres en todos los tiempos "son desagradecidos, cambiantes y disimuladores, huidizos en los peligros, ávidos de privilegios" de modo que "un príncipe que se apoya enteramente en su palabra, si le faltan otras disposiciones caerá". La implicación es que "un príncipe, y sobre todo un príncipe que sea nuevo" debe siempre -no solo ocasionalmente- verse forzado por la necesidad a actuar "contrariamente a la humanidad" si quiere mantener su posición y evitar ser engañado (Skinner, 1991:57).

Tenemos aquí enunciada, -como no- lo que constituye la famosa y discutida concepción antropológica de nuestro autor: la perversidad de la naturaleza humana y la recomendación descarnada al príncipe a actuar en consecuencia, lo cual es ser más perverso que aquellos y utilizar todas las artes del engaño para lograr sus objetivos.

Insistirá en el capítulo 18 en que la práctica de la hipocresía no es indispensable únicamente para el gobierno del príncipe, sino que puede mantenerse sin mucha dificultad tanto tiempo como lo requiera. Dos razones aduce al respecto: la candidez humana y sobre todo la proclividad al autoengaño, que los hace tomar las cosas en su apariencia acrítica. La otra es que 
cuando deben valorar la conducta del príncipe, hasta los más perspicaces juzgarán según las apariencias. Aislado del pueblo, protegido por "la majestad del gobierno", la posición del príncipe es tal que "cada cual ve lo que aparentáis ser" pero "pocos perciben lo que sois". Por tanto, no hay razón para suponer que vuestros pecados os descubran; por el contrario, "un príncipe que engaña, siempre encuentra hombres que se dejan engañar a sí mismos".

Refiriéndose acerca de la actitud que deben tomar los príncipes frente a las nuevas normas por él señaladas, a primera vista parece adoptar una postura relativamente convencional; en el capítulo 15 se muestra de acuerdo en que "sería muy de alabar" en los nuevos príncipes el exhibir aquellas cualidades que normalmente son consideradas buenas y equipara el abandono de las virtudes principescas con el proceso de aprender a "no ser bueno". Preguntándose sobre: ¿Cómo el príncipe debe mantener sus promesas?, el florentino afirma que todo mundo constata cuan digno de alabanza es el que un caudillo "viva con sinceridad y no con engaño" y continúa insistiendo en que un príncipe no debe simplemente aparecer convencionalmente virtuoso, sino que debe "serlo realmente" cuando esté en su mano, "observando lo que es recto cuando pueda" y dejando de lado las virtudes cuando lo dicte la necesidad".

No obstante, en el capítulo 15 se introducen dos argumentos muy distintos, cada uno de los cuales es desarrollado seguidamente. Ante todo, Maquiavelo se muestra un tanto burlón acerca de si se puede decir con propiedad que aquellas cualidades que se consideran buenas, pero que son sin embargo ruinosas, merecen realmente el nombre de virtudes. Puesto que son proclives a acarrear la destrucción, prefiere decir que "parecen virtudes", y puesto que sus opuestas aparecen más aptas para aportar "seguridad y bienestar", prefiere decir que "parecen vicios (Skinner, 1991:60).

Nuestro autor ejemplificará esta tesis en los dos siguientes capítulos. En el 16 se referirá a la liberalidad y a la mezquindad, con la que debe actuar el príncipe, tema tratado por los humanistas clásicos, y al cual Maquiavelo le da una vuelta total en su formulación. Concluye que si un príncipe, comienza con abandonar cualquier deseo de actuar con magnificencia, podrá ser tildado de miserable al principio, pero "en el curso del tiempo será considerado más $\mathrm{y}$ 
más liberal" y practicará de hecho la verdadera virtud de la liberalidad.

En el capítulo 17, respondiendo a la pregunta de si "¿Es mejor ser amado que ser temido?", Maquiavelo enfatiza que: "Es mucho más seguro para el príncipe, ser temido que ser amado". La razón estriba en que muchas de las cualidades que hacen a un príncipe amado tienden también a atraerle el desprecio. Si vuestros súbditos no "tienen miedo al castigo" aprovecharán cualquier ocasión para engañaros en su propio provecho. Pero si os hacéis temer, dudarán en ofenderos o injuriaros, a resultas de lo cual se os hará mucho más fácil mantener vuestro estado (Skinner, 1991:61).

Como podemos apreciar, estos capítulos vertebran la llamada, por Skinner, revolución de Maquiavelo, y en síntesis nos permite valorar la propuesta ética del autor que podemos sintetizar de la siguiente manera. A la acusación respecto de la inmoralidad del planteamiento maquiavélico, advirtamos que no hay tal, sino que lo que existe es una secularización de la política, una autonomización, la cual se convierte en una técnica acerca de cómo gobernar, de cómo dominar a los hombres. La política, como el arte de gobernar, establece sus propios valores: lo bueno es aquello que me sirve para ganar, lo malo es aquello que me lleve a perder. En nombre del poder todo se vale. Es el dictum famoso: El fin justifica los medios.

A este respecto, como perspicazmente señala el teórico argentino Eduardo Grüner, "Maquiavelo no es alguien que sirve, simplemente, para aprobar exámenes de Teoría Política. Es alguien que sirve para vivir "políticamente". Agrega a continuación, que su carácter como autor clásico que le viene dado por ser alguien que nos viene a recordar que las preguntas que él se plantea pueden y deben ser reformuladas, que cada generación tiene abiertas las puertas de la construcción de su futuro. En el caso que nos ocupa, no se trata de una construcción cualquiera: se trata nada más y nada menos que de la construcción de la polis; de la ciudad de los hombres, de la trama societal que en cada momento histórico redefine la relación dominadores/ dominados, que le da su carnadura y su nervadura, su sangre y su barro.

Niccoló Macchiavelli, el secretario florentino es un clásico de esa naturaleza y de esa estatura. El primer "escritor sombrío de la burguesía" (como alguna vez lo 
definió Adorno, equiparándolo a Sade o a Nietzsche, es decir a aquellos productos de la cultura burguesa de los que la burguesía se apresuró a renegar, puesto que iban mucho más allá de lo tolerable) fue ferozmente combatido, denostado y difamado por aquellos mismos a los que con sus ideas contribuyó a llevar al poder; los propios términos de "maquiavelismo" o maquiavélico" -verdaderos automatismos del lenguaje que inconscientemente trasmiten su carga negativa- son la rémora infame de ese ocultamiento ideológico. Lo cual es fácilmente comprensible: toda clase dominante, una vez consolidado su poder, necesita rápidamente borrar sus orígenes bastardos, ocultar la huella de la violencia original de su nacimiento, esconder la realidad desagradable y sangrienta de su conquista detrás de la mascara alegre, pacífica y bonachona de las ideas abstractas de Ley, Justicia, Constitución o Contrato. La burguesía, ya a partir del siglo XVIII pero mucho más luego de la afirmación de su poder con la Revolución Industrial, preferirá despachar al incómodo Maquiavelo (y a Hobbes) y retener al ponderado Locke (y a Montesquieu, que le proporciona un justificativo mucho más tranquilizador, más idealizado y elegante, para su República de Propietarios: es decir para su dominación de clase (Grüner, 1999:253).

A su juicio, el florentino tiene el inconveniente de que, justamente, por estar situado en la etapa de transición que da origen al poder burgués, puede darse el lujo -e incluso está obligado- a decir claramente lo que los posteriores ideólogos de la burguesía consolidada más recatados tienen que ocultar y mistificar: que la política es, ante todo, nos guste o no, dominación; que las estrategias de obtención tanto como de las de conservación del poder de dominar suponen necesariamente una economía de la violencia con la que muy poco tienen que ver las ampulosas declaraciones de amor a Dios, o a otras deidades menos trascendentales, sea esta la Humanidad con mayúscula, o el todopoderoso Partido, cuando no las lágrimas de cocodrilo vertidas por el sufrimiento de las víctimas, o la hipocresía de los victimarios que, mientras pretenden hacer el Bien sin mirar a quien, aplastan 
a sangre y fuego a quienes tienen opiniones divergentes sobre qué cosa es el Bien; que, por lo tanto, -y es esto lo escandaloso en Maquiavelo-, hacer política no tiene un cuerno que ver con la búsqueda del Interés General, y mucho con la decisión de a quién (a qué clases, a qué grupos sociales, a qué perspectivas, ideales y materiales de construcción de la polis) se va a beneficiar, y quién se va a perjudicar.

Y que, una vez tomada la decisión y definido el objetivo, es necesario hacer lo necesario para satisfacerlo: es necesario darse la estrategia, la teoría, la técnica, la pragmática y la potencia para que la correlación de fuerzas -ya que si la política es la dialéctica entre dominadores y dominados, entonces es antes el reino del conflicto que el del consenso, consenso que no es sino el efecto de la correlación de fuerzas- nos sea favorable. Eso es la política (empezando por la propia política burguesa que Maquiavelo objetivamente favoreció) y no la mediocre y descafeinada declaración de principios jesuíticos $\mathrm{y}$ moralizantes tendientes a esconder lo que se hace detrás de lo que se dice (Grüner, 1999:254).

Es conocido, como especialmente gracias a la lectura del teórico italiano Antonio Gramsci; el primero en saludar en Maquiavelo al verdadero fundador, tres siglos y medio antes de Marx, de lo que el marxista italiano llamaría filosofía de la praxis: en la dialéctica de los "medios" y los "fines" (en lo que Max Weber, y más tarde, la Escuela de Frankfurt nombrarían como "racionalidad formal/instrumental" y "racionalidad sustancial/material" Gramsci lúcidamente supo ver no la separación sino, por el contrario, la necesaria articulación conflictiva y abierta entre teoría y práctica, entre ética y política, entre el pensamiento y la acción, entre los ideales y la estrategia para llevarlos a cabo. Con ello, la interpretación gramsciana de Maquiavelo se opone radicalmente a su lectura burguesa, -a cuyos ejemplos más notables nos referíamos al inicio de este escrito-, un ejemplo tomado del citado Grüner; la dialéctica "coerción/ consenso (la concepción maquiaveliana de que la fuerza pura, por más materialmente potente que sea, no alcanza para conquistar el poder, y menos para mantenerlo), conduce- a través de la analogía entre el Individuo-Príncipe de la era renacentista y el ColectivoPartido Revolucionario de la era moderna como respectivos mediadores entre "sociedad política" y 
"sociedad civil" -a nociones decisivas para la teoría política contemporánea como son las de hegemonía y la distinción entre guerra de movimientos y guerra de posiciones.

Estas ideas extraídas de una lectura activa y productiva de los textos de Maquiavelo, no solamente constituyen una sólida alternativa a la teoría política burguesa (con su distinción ideológica, cimentada ya a partir de Hobbes pero sobre todo de Locke, entre lo "político" y lo "social-económico", distinción tendiente a ocultar las mutuas determinaciones entre ambos planos, y que se traduce en una práctica fetichista de la "representación" política por la cual de hecho la decisión política tanto como la económica-social queda en manos de las clases dominantes, mientras el resto de la sociedad se limita a sufrirla pasivamente), sino que son anticipación genial de la importancia que los factores ideológicos-culturales generadores de "consenso"- y por lo tanto de su estatuto de "campo de batalla" de las hegemonías y contra hegemonías- tendrían en toda la política del siglo $\mathrm{XX}$, ya sea que queramos reconocerlo o no. Pero si esta "genialidad" se debe sin duda al "genio" de Gramsci, no es menos cierto que encontró en Maquiavelo, y en nadie más (aparte, obviamente, de sus casi contemporáneos; Marx y Lenin) el pre-texto para su hallazgo (Grüner, 1999: 257).

\section{Conclusión: La terca}

\section{actualidad de Maquiavelo}

Maquiavelo no es solo, qué duda cabe, nuestro contemporáneo, sino el gran teórico de la modernidad. Lo es porque generó un conjunto de conceptos teórico-prácticos y una actitud hacia la política que, a casi cinco siglos de su nacimiento en los albores de la Modernidad (léase del modo de producción capitalista), pueden ser vueltas como un guante para utilizarlas como "armas de la crítica" contra sus primitivos beneficiarios, tan deseosos ahora de mandarlo al basurero de la Historia. En este sentido, siguiendo el esclarecedor análisis del mencionado Grüner, nos parece ociosa -cuando no interesada y engañosa- la oposición, postulada por algunos, entre un Maquiavelo "monárquico" o "autocrático" (el de El Príncipe) y un Maquiavelo "republicano" o "democrático" (el de Los Discursos...).

Semejante "dualización" esquizofrenizante podría fácilmente ser el último, y el más insidioso de los trucos para desembarazarse de los rasgos más inquietantes del "maquiavelismo", para neutrali- 
zar mediante alguna nueva versión del "justo medio" el carácter incómodamente extremo -es decir "radical" y exento de concesiones y componendas- de un pensamiento que en sí mismo no es ni "monárquico" ni "republicano" (esto no es más que el anecdotario de las oportunidades históricas del hombre Maquiavelo), sino que, como un implacable cirujano que no vacila en el momento de la verdad, hunde su escalpelo en las mismas raíces del Mal, y así se transforma en un relámpago de lucidez utilizable como potencial instrumento de análisis critico e insobornable de toda forma de dominación, cualquiera sean sus vestiduras(que no son, por supuesto, todas iguales) (Grüner, 1999:258:).

Esta es la manera en que lo ha leído la tradición crítica arriba señalada, y esta es la manera en que quisiéramos modestamente nosotros se leyera aquí, sin ninguna pretensión de "objetividad": una pretensión que no es más que la engañifa de una "ciencia" política desesperada por olvidar lo más rápidamente la lección central del genial florentino, a saber, que la política es un arte, es decir, es una práctica de la pasión y del compromiso, de una toma de "partido" donde la única "objetividad" posible y auténtica es la de la explícita y frontal elección de un bando.

Siguiendo la analítica del mencionado comentarista, señalemos cómo la conformación de los Estados modernos -aunque sea, en principio, bajo el ropaje del "derecho divino" de los monarcas absolutistas- arroja como efecto objetivo la secularización, y a su vez ésta es una condición para el completamiento y la estabilización de aquélla. El ordenamiento territorial-administrativo del mercado interno, del comercio exterior y de la circulación del dinero requiere un Estado fuerte, centralizado, planificador, recaudador de impuestos, controlador de los flujos migratorios, con poder de represión propio y políticamente al servicio de sus intereses (el "ejército nacional" profesionalizado será una obsesión de Maquiavelo, en contraposición a los "ejércitos privados" de los señores feudales del período anterior). Con una diplomacia reciamente defensora de esos mismos intereses: en definitiva, con una acabada autonomía de decisión respecto de los "otros" poderes que disputan la hegemonía sobre el mundo de los hombres de entonces. Para la Italia fragmentada y balcanizada del siglo XVI -aunque desde luego no sólo para 
ella- el poder que representa el principal obstáculo para la conquista de la unidad bajo un Estado nacional que permita el desarrollo de las nuevas relaciones de producción emergentes es, como no podía ser de otra forma, el poder "globalizado" del Papado y de la Iglesia Romana: poder "espiritual" (léase: ideológico-cultural) y simultáneamente "secular" (léase económico y político-militar), donde se podría decir- aún a riesgo de caer en cierta simplificación- que su "espiritualidad" no es sino la gigantesca racionalización, preparada por lo menos desde San Pablo y San Agustín, de la "obtención y conservación" del poder político y económico.

Maquiavelo sabe perfectamente contra qué está luchando, más aún: en cierto sentido su argumentación toma algunas de sus principales armas teóricas y retóricas, incluso algunas de sus metáforas más eficaces, de la propia práctica del poder papal, sólo que para volverlas en su contra: ¿Acaso no es el poder papal el ejemplo paradigmático de esa combinación del Zorro y el León, de la astucia calculadora y la fuer- za bruta, que Maquiavelo reputa como indispensable al carácter del verdadero Príncipe? ¿Acaso la Iglesia Católica no es asimismo el ejemplo paradigmático de la articulación entre coerción y consenso, entre temor $y$ amor (el mayor consenso y el mayor "amor", por cierto, que ideología alguna haya logrado en Occidente antes del capitalismo) que está en la base maquiaveliana de lo que Gramsci llamaría hegemonía? ¿Acaso el ya mencionado "derecho divino" de las monarquías absolutas no traduce la pretensión papal de ser el representante infalible de la voluntad de Dios en la Tierra?¿Acaso la Iglesia Católica no ha sabido aprovechar como ningún otro poder (otra vez, antes de la emergencia del capitalismo) los factores "objetivos" de la fortuna y los "subjetivos" de la virtú cuyo equilibrio es la estofa misma del saber político en Maquiavelo (Grüner, 1999:261).

En síntesis, respondiendo a nuestra inquietud inicial respecto a la modernidad y actualidad del pen- 
samiento de Maquiavelo, señalemos -siguiendo a Grüner- los rasgos más señalados de esta:

Lo muestra su modernísima, casi protomarxista y protofoucaultiana noción del Poder como una relación social y un dispositivo de interpelación generador de hegemonía - para el grupo dominante que sea o para el que le dispute el poderen los intrincados intersticios de la "sociedad civil" (¿para qué sino esa obsesión con la compleja dialéctica entre el "amor" y el temor" (Grüner) antes que como una institución estática destinada a "representar" los intereses "generales".

Lo muestra finalmente, y a riesgo de repetirnos, la lúcida disposición a no ocultar ni ocultarse la estructura constitutivamente violenta de la historia y de la Política, atravesada por la lucha de clases y en general por el conflicto social del cual, como hemos visto, el florentino era perfectamente consciente, y desprovista de las consolaciones facilongas y las mascaradas hipócritas con las que tanta "ciencia" política "moderna" esconde su (intencional o no, poco importa) servidumbre a la globalizada ideología dominante (Grüner, 1999:266-67).
No nos interesa, entonces, preguntarnos si nuestro Maquiavelo es o no un "científico", si es "autoritario" o "democrático", si es de derecha, de izquierda o de centro. Nos limitaremos a intentar hacernos merecedores de su principal enseñanza: que la Historia y la Política son una zona de y en conflicto, en perpetuo proceso de redefinición en la lucha por la refundación permanente de la polis, una lucha que compete $y$ compromete a todos y a cada uno de los sujetos sociales y políticos, y que se desarrolla en la praxis cotidiana, "dentro" o "fuera" de las "instituciones" y de la cultura en su sentido más amplio. La conclusión que se desprende de esta enseñanza sólo puede ser una y es que el "clásico" Maquiavelo todavía no es esto, aquello o lo de más allá: Maquiavelo es un campo de batalla.

\footnotetext{
Bibliografía.

Cassirer, Ernst (1968), El mito del estado. México, F.C.E.

Cardona de Gilbert, Angeles (1973), El Príncipe: Estudio preliminar, Barcelona, Editorial Bruguera.

Cortés Rodas, Francisco (2001), La política y la violencia en el pensamiento de Maquiavelo. En Estudios Políticos, Colombia, No. 19.
} 


\section{ESPICA}

Gramsci, Antonio (1980), Maquiavelo y Lenin: notas para una teoría política marxista, México, Editorial Diógenes.

Grüner, Eduardo (1999), "La astucia del león y la fuerza del zorro. Maquiavelo, entre la verdad de la política y la política de la verdad", en La Filosofía Política Clásica. De la Antigüedad al Renacimiento (Atilio A. Baron.Comp.), Buenos Aires, CLACSO/ EUDEBA.

Habermas, Jurgüen (1990), Teoría y Praxis, Editorial Tecnos, Madrid.

Sabine, George H (1972), Historia de la Teoría Política, México, F.C.E.

Skinner, Quentin (1991), Maquiavelo, Madrid, Alianza Editorial.

Magazine, Litteraire (2001), L' enigme Machiavel, Paris, n. ${ }^{\circ} 397$. 